\title{
Effects of diurnal warming on soil respiration are not equal to the summed effects of day and night warming in a temperate steppe
}

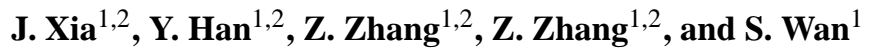 \\ ${ }^{1}$ State Key Laboratory of Vegetation and Environmental Change, Institute of Botany, Chinese Academy of Sciences, \\ Xiangshan, Beijing 100093, China \\ ${ }^{2}$ Graduate School of Chinese Academy of Sciences, Yuquanlu, Beijing 100049, China
}

Received: 18 March 2009 - Published in Biogeosciences Discuss.: 21 April 2009

Revised: 23 July 2009 - Accepted: 23 July 2009 - Published: 3 August 2009

\begin{abstract}
The magnitude of daily minimum temperature increase is greater than that of daily maximum temperature increase under climate warming. This study was conducted to examine whether changes in soil respiration under diurnal warming are equal to the summed changes under day and night warming in a temperate steppe in northern China. A full factorial design with day and night warming was used in this study, including control, day (06:00 a.m.-06:00 p.m., local time) warming, night (06:00 p.m.-06:00 a.m.) warming, and diurnal warming. Day warming showed no effect on soil respiration, whereas night warming significantly increased soil respiration by $7.1 \%$ over the 3 growing seasons in 20062008. The insignificant effect of day warming on soil respiration could be attributable to the offset of the direct positive effects of increased temperature by the indirect negative effects via aggravating water limitation and suppressing ecosystem $\mathrm{C}$ assimilation. The positive effects of night warming on soil respiration were largely due to the stimulation of ecosystem $\mathrm{C}$ uptake and substrate supply via overcompensation of plant photosynthesis. Changes in both soil respiration $\left(+20.7 \mathrm{~g} \mathrm{C} \mathrm{m}^{-2} \mathrm{y}^{-1}\right)$ and GEP $\left(-2.8 \mathrm{~g} \mathrm{C} \mathrm{m}^{-2} \mathrm{y}^{-1}\right)$ under diurnal warming are smaller than their summed changes $(+40.0$ and $+24.6 \mathrm{~g} \mathrm{C} \mathrm{m}^{-2} \mathrm{y}^{-1}$, respectively) under day and night warming. Our findings that the effects of diurnal warming on soil respiration and gross ecosystem productivity are not equal to the summed effects of day and night warming are critical for model simulation and projection of climatecarbon feedback.
\end{abstract}

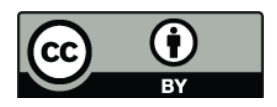

Correspondence to: S. Wan (swan@ibcas.ac.cn)

\section{Introduction}

With the unprecedented magnitude of global temperature rising associated with anthropogenic activities since industrial revolution, it is of great concern how the terrestrial biosphere responds and feeds back to climate change, especially through carbon (C) cycling (Luo et al., 2009). In the past decades, findings from temperature manipulation experiments have greatly improved our understanding of the impacts of climate warming on terrestrial $\mathrm{C}$ cycling. However, many uncertainties remain to be addressed. For example, historical meteorological records and model projections reveal a warming trend that is more pronounced at night than day (Karl et al., 1991; Easterling et al., 1997; IPCC, 2001; Zhou et al., 2007). Although such an asymmetric diurnal warming is still under debate (Vose et al., 2005; IPCC, 2007), it has been widely observed over the land surface since 1950 (Easterling et al., 1997; Zhou et al., 2007). From the perspective of plant ecophysiology, since plant photosynthesis occurs during daytime whereas there is only plant respiration at night, day and night warming may have different impacts on plant and ecosystem $\mathrm{C}$ uptake and release. This in turn would influence the balance of these two aspects for both plants and ecosystems. In fact, differential responses of plant growth and crop yield to increased daily minimum vs. maximum temperature have been demonstrated by manipulative experiments (Ziska and Manalo, 1996; Volder et al., 2007), long-term observations (Stooksbury and Michaels, 1994; Nicholls, 1997; Alward et al., 1999; Peng et al., 2004; Schlenker and Roberts, 2006; Lobell and Ortiz-Monasterio, 2007; Lobell, 2007), and model simulations (Rosenzweig and Tubiello, 1996; Dhakhwa and Campbell, 1998). At the ecosystem scale, Wan et al. (2009) have recently found

Published by Copernicus Publications on behalf of the European Geosciences Union. 
differential impacts of day (negative) and night warming (positive) on gross ecosystem productivity (GEP) and net ecosystem productivity (NEP) in a semiarid temperate steppe in northern China.

Previous observations suggest that day and night warming could differentially affect ecosystem $C$ processes. However, most of the manipulative experiments (Rustad, 2008) were conducted with diurnal or constant warming so far. To the best our knowledge, only a few experiments have been designed to examine the effect of night warming on ecosystem $C$ processes, and day warming was not included in these studies (Volder et al., 2004; Beier et al., 2008). In order to better understand the mechanisms controlling ecosystem $\mathrm{C}$ processes and to convincingly project climate change-carbon feedback under the diurnally asymmetric climate warming, it is essential to examine the effects of day and night warming separately and to compare their summed effects with the effects of diurnal warming. If the summed effects of day and night warming are not equal to those of diurnal warming, we can not predict the responses of terrestrial $\mathrm{C}$ cycling to diurnally asymmetric climate warming based on diurnal or constant warming treatment.

As the second largest $\mathrm{C}$ flux between terrestrial ecosystems and the atmosphere, soil respiration plays an important role in regulating ecosystem $\mathrm{C}$ cycling and climate-carbon feedbacks. Temporal and spatial variability of soil respiration is generally associated with changes in temperature and water availability (Lloyd and Taylor, 1994; Davidson and Janssens, 2006; Luo and Zhou, 2006; Luo, 2007). Moreover, as a substrate-regulated process, it has been widely reported that soil respiration is tightly coupled with ecosystem $\mathrm{C}$ uptake which determines the availability of $\mathrm{C}$ supply to respiratory activities (Högberg et al., 2001; Wan and Luo, 2003; Tang et al., 2005; Bahn et al., 2008). Thus, responses of soil respiration to climate warming cannot be fully assessed if it is taken as an isolated belowground soil process without considering aboveground $\mathrm{C}$ assimilation.

Here, we present the results from a field study to investigate effects of day and night warming on soil respiration with four treatments, including control, day (06:00 a.m.-06:00 p.m., local time) warming, night (06:00 p.m.-06:00 a.m.) warming, and diurnal warming in a semiarid temperate steppe in northern China since 2006. Historical meteorological data records in this region have shown greater increases in daily minimum than that maximum temperature over the past half century (Wan et al., 2009). Given that the day and night warming have differential effects on GEP in this ecosystem (Wan et al., 2009), we expect that soil respiration differently responds to day and night warming. We specifically addressed the following three questions in this study: (1) does soil respiration differentially respond to day and night warming? (2) are the effects of diurnal warming equal to and predicted by the summed effects of day and night warming? and (3) what are the main drivers for soil respiration in response to day and night warming?

\section{Materials and methods}

\subsection{Study site}

The research was conducted in a semiarid temperate steppe in Duolun County $\left(42^{\circ} 02^{\prime} \mathrm{N}, 116^{\circ} 17^{\prime} \mathrm{E}, 1324 \mathrm{~m}\right.$ a.s.l.) in Inner Mongolia, China. The grassland is dominated by $\mathrm{C}_{3}$ grasses - Stipa krylovii Roshev., Agropyron cristatum (L.) Gaertn.; $\mathrm{C}_{4}$ grass - Cleistogenes squarrosa (Trin.) Keng.; and $\mathrm{C}_{3}$ forbs - Artemisia frigida Willd., Potentilla acaulis L., Allium bidentatum Fisch. ex Prokh. Long-term (19532007) mean annual precipitation (without the precipitation fall as snow) is approximately $383 \mathrm{~mm}$ with $90 \%$ of the precipitation falling from May to October. Mean annual temperature is $2.1^{\circ} \mathrm{C}$ with monthly mean temperature ranging from $18.9^{\circ} \mathrm{C}$ in July to $-17.5^{\circ}$ in January. The sandy soil of the study site is classified as chestnut according to the Chinese classification, or Haplic Calcisols according to the FAO classification. Mean bulk density is $1.31 \mathrm{~g} \mathrm{~cm}^{-3}$ and $\mathrm{pH}$ is 7.7 .

\subsection{Experimental design}

We used a complete random block design with 6 treatments, including control (C), day warming (06:00 a.m.-06:00 p.m.; D), night warming (06:00 p.m.-06:00 a.m.; N), diurnal ( 24 h; W) warming, nitrogen addition, and diurnal warming plus nitrogen addition, and replicated each treatment 6 times (Wan et al., 2009). Thirty-six $3 \times 4 \mathrm{~m}$ plots were arranged in $6 \times 6$ matrix, with a $3 \mathrm{~m}$ distance between any two adjacent plots. The effects of nitrogen addition and warming plus nitrogen addition on ecosystem $\mathrm{C}$ processes were reported in a previous study (Xia et al., 2009) and not included in this study. In late August 2005, we compared ecosystem C fluxes (gross ecosystem exchange, ecosystem respiration, and net ecosystem exchange), aboveground biomass, and root biomass in the plots which would be assigned to different treatments in 2006 and did not find any statistically significant difference (all $P>0.05$ ). The warmed plots were heated continuously by MSR-2420 infrared radiators (Kalglo Electronics Inc, Bethlehem, PA, USA) suspended $2.25 \mathrm{~m}$ above the ground. In each control plot, one "dummy" heater with the same shape and size as the infrared heater was suspended $2.25 \mathrm{~m}$ above ground to simulate the shading effects of the infrared radiator. All the heaters under the warming treatments were set at a radiation output of approximately 1600 watts. The warming treatment commenced on 23 April 2006.

\subsection{Measurements}

To measure soil respiration, two PVC collars $(11 \mathrm{~cm}$ in internal diameter and $5 \mathrm{~cm}$ in height) were inserted $2-3 \mathrm{~cm}$ into the soil at two opposite corners in each plot. All living plants inside the soil collars were removed by hand at least one day prior to the measurements to exclude plant respiration from the aboveground parts. A LI-8100 portable soil $\mathrm{CO}_{2}$ fluxes system (Li-Cor, Inc., Lincoln, NE, USA) was used to 
measure diurnal cycles (twice a month at 3-h intervals) of soil respiration. A soil $\mathrm{CO}_{2}$ Flux Chamber attached to LI-8100 was put 1-2 min on each collar to measure soil respiration and then move to the next collar.

Soil temperature $\left({ }^{\circ} \mathrm{C}\right)$ at the depth of $10 \mathrm{~cm}$ was measured adjacent to each PVC collar using a thermocouple probe (Li-8100-201) connected to the Li-8100 at the same time of soil respiration measurement. Volumetric soil moisture (0$10 \mathrm{~cm}$ ) was measured using a portable soil moisture device (Diviner 2000, Sentek Pty Ltd., Balmain, Australia) adjacent to the PVC collars between 09:00-12:00 on the same day of soil respiration measurement.

Ecosystem C fluxes were measured twice a month at 3-h intervals at the same time of soil respiration measurement. We first measured net ecosystem C exchange (NEE) with a transparent chamber $(0.5 \times 0.5 \times 0.5 \mathrm{~m})$ attached to an infrared gas analyzer (IRGA; LI-6400, LiCor, Lincoln, NE, USA). The chamber was placed and sealed on an aluminum frame $(0.5 \times 0.5 \mathrm{~m})$ inserted $2-3 \mathrm{~cm}$ into the soil at two corners of each plot. The PVC collars for soil respiration measurement were inside the frames in order to relate soil respiration with ecosystem $\mathrm{C}$ fluxes. This static-chamber method has been successfully used to evaluate plot-level fluxes of $\mathrm{CO}_{2}$ in this ecosystem (Niu et al., 2008; Xia et al., 2009). The polyethelene sheeting used for chamber construction allows $>90 \%$ of photosynthetic active radiation to pass into the chamber. Two small fans continuously mixed the air inside the chamber during measurement. Consecutive recordings of $\mathrm{CO}_{2}$ concentrations were taken during a 90-s period after steady-state conditions were achieved within the chamber for 20 s. Following the NEE measurement, the chamber was vented, replaced on each frame and covered with an opaque cloth. Because of elimination of light (and hence photosynthesis), the values of $\mathrm{CO}_{2}$ exchange represented ecosystem respiration (ER). We measured ER from 06:00 to 18:00 (06:00, 09:00, 12:00, 15:00) and NEE at both day- and night-time (06:00, 09:00, 12:00, 15:00, 18:00, 21:00, 00:00, and 03:00). In fact, values of NEE in night were equal to those of ER. Across the growing seasons, because sun rises around 05:00 and sets at about 19:00, gross ecosystem exchange (GEE) was calculated as the difference between NEE and ER from 06:00 to 18:00. We considered $\mathrm{C}$ uptake (GEE) to be negative and $\mathrm{C}$ release (ER and SR) to be positive. Thus, GEE in this study was equal to NEE - ER. After that, gross ecosystem productivity (GEP) was calculated by multiplying daily integrated values of GEE (Wan et al., 2009). In order to examine impacts of treatments on ecosystem water use efficiency (WUE), we first calculated evapotraspiration (ET) from the time-courses of the $\mathrm{H}_{2} \mathrm{O}$ concentration, then WUE was calculated as GEE divided by $\mathrm{ET}$ (WUE=|GEE|/ET).

Leaf-level gas exchange of $S$. krylovii was monitored at 3-hour intervals (06:00, 09:00, 12:00, 15:00, 18:00, 21:00, 00:00, and 03:00 local time), using LI-6400 Portable Photosynthesis System. One individual S. krylovii plant was selected to measure leaf photosynthesis in each plot. In late August from 2006 to 2008, we clipped aboveground biomass of forty $1 \times 1 \mathrm{~m}$ plots near our experimental plots. Living plant aboveground tissues were separated from dead tissues, oven-dried, and weighted. The data showed that, across 2006 to 2008, S. krylovii represented $13.2 \%$ and $45.6 \%$ of the aboveground biomass for total community and grass species, respectively. Sugar and starch concentration was measured by enthrone method (see details in Wan et al., 2009) and a UV-VIS7500 spectrophotometer (Techcomp, Shanghai, China).

\subsection{Data analysis}

Three-way ANOVAs were used to examine effects of year, day warming, night warming, and their possible interactions on soil respiration, soil temperature, soil moisture, and GEP. Two-way ANOVAs were used to examine effects of day and night warming on soil respiration in different months. Data from all rings were used in the ANOVA analyses. Effects of the experimental treatments on soil respiration were presented as the absolute (Mean treatment $\left.^{-} \mathrm{Mean}_{\text {control }}\right)$ and relative ((Mean treatment $\left.\left.-\mathrm{Mean}_{\text {control }}\right) / \mathrm{Mean}_{\text {control }}\right)$ differences between the mean values of the warmed and control plots. Since the total heating time and energy inputs in the day and night warming plots were identical compared to those in the diurnal warming plots, we took the sum of day and night warming effects as the predicted effects of whole-day warming and the measured effects of diurnal warming as the observed ones. By pooling the data from all observational days, we plotted the predicted effects against the observed effects (Fig. 6). The slopes of the linear regression were investigated to determine if they were significantly different from the $1: 1$ line. If the regression slope did not overlap with the 1:1 line, diurnal warming effects were not equal to the summed effects of day and night warming (Zavaleta et al., 2003). Simple and multiple linear regression analyses were used to examine relationships between soil respiration and soil temperature, soil moisture, GEE, and leaf photosynthesis. All statistical analyses were conducted with SAS software (SAS Institute Inc., Cary, NC, USA).

\section{Results}

\subsection{Soil microclimate and substrate supply}

Soil temperature at $10 \mathrm{~cm}$ depth varied among the 3 growing seasons $(P<0.0001$; Table 1$)$, ranging from $15.2^{\circ} \mathrm{C}(2008)$ to $18.2^{\circ} \mathrm{C}$ (2007) with an average of $17.0^{\circ} \mathrm{C}$ in the control plots. Both day $(P<0.0001)$ and night $(P<0.0001)$ warming significantly elevated daily mean soil temperature across the 3 growing seasons (Table 1, Fig. 1a). As expected, night warming caused greater increase in nighttime mean soil temperature $\left(0.38^{\circ} \mathrm{C}\right)$ than day warming $\operatorname{did}\left(0.17^{\circ} \mathrm{C}\right)$. However, no difference was found between the changes in daytime mean temperature induced by day $\left(0.47^{\circ} \mathrm{C}\right)$ and 
Table 1. Results ( $P$-values) of three-way ANOVAs on the effects of day (D) and night (N) warming and their interactions on soil respiration (soil R), soil temperature (soil T), soil moisture (soil M), and gross ecosystem productivity (GEP).

\begin{tabular}{lrrrr}
\hline Source of variance & Soil $\mathrm{R}$ & Soil T & Soil M & GEP \\
\hline Year & $<.0001$ & $<.0001$ & $<.0001$ & $<.0001$ \\
$\mathrm{D}$ & 0.978 & $<.0001$ & 0.006 & 0.025 \\
$\mathrm{~N}$ & 0.001 & $<.0001$ & 0.027 & 0.051 \\
$\mathrm{D} \times \mathrm{N}$ & 0.124 & 0.462 & 0.854 & 0.137 \\
$\mathrm{D} \times$ Year & 0.807 & 0.498 & 0.759 & 0.837 \\
$\mathrm{~N} \times$ Year & 0.216 & 0.290 & 0.927 & 0.933 \\
$\mathrm{D} \times \mathrm{N} \times$ Year & 0.799 & 0.956 & 0.813 & 0.759 \\
\hline
\end{tabular}

night warming $\left(0.46^{\circ} \mathrm{C}\right)$. As a result, daily mean soil temperature showed a larger increase under night $\left(0.42^{\circ} \mathrm{C}\right)$ than day $\left(0.32^{\circ} \mathrm{C}\right)$ warming. No interactive effect between day and night warming $(P=0.462)$ on soil temperature was observed. In addition, no interaction was found between year and day warming $(P=0.498)$, night warming $(P=0.290)$, or their combination ( $P=0.956$; Fig. 1a).

Similar to soil temperature, volumetric soil moisture at $0-10 \mathrm{~cm}$ depth fluctuated greatly among the growing seasons $(P<0.0001$; Table 1$)$. Both day $(P=0.006)$ and night $(P=0.027)$ warming significantly reduced volumetric soil moisture, but no interactions $(P=0.854)$ were observed (Table 1, Fig. 1a). Night warming caused a slightly lower reduction $(0.31 \mathrm{v} / \mathrm{v} \%$, absolute difference) in soil moisture than day warming did $(0.39 \mathrm{v} / \mathrm{v} \%)$. No interaction between year and day warming $(P=0.759)$, night warming $(P=0.927)$, or their combination $(P=0.813)$ was detected on soil moisture (Table 1). At ecosystem level, day and night warming showed differential impacts on water use efficiency (WUE). Across the 3 growing seasons, ecosystem WUE was significantly reduced by day warming $(P=0.002)$ whereas was enhanced by night warming $(P=0.047)$ in this study (Fig. 2$)$.

In contrast to effects of day and night warming on soil temperature and moisture, day and night warming showed opposite influences on GEP (Fig. 1b). Day warming significantly reduced GEP by $4.68 \%\left(20.75 \mathrm{~g} \mathrm{~m}^{-2} \mathrm{yr}^{-1} ; P=0.025\right)$, whereas night warming marginally increased GEP by $4.24 \%$ $\left(17.99 \mathrm{~g} \mathrm{~m}^{-2} \mathrm{yr}^{-1} ; P=0.051\right)$ over the 3 growing seasons (Fig. 1b) (Wan et al., 2009). No interaction between day and night warming ( $P=0.137)$ was detected to impact GEP over the 3 growing seasons. In addition, there was no interaction between year and day warming $(P=0.837)$, night warming $(P=0.933)$, or their combination $(P=0.759)$ to affect GEP (Table 1).

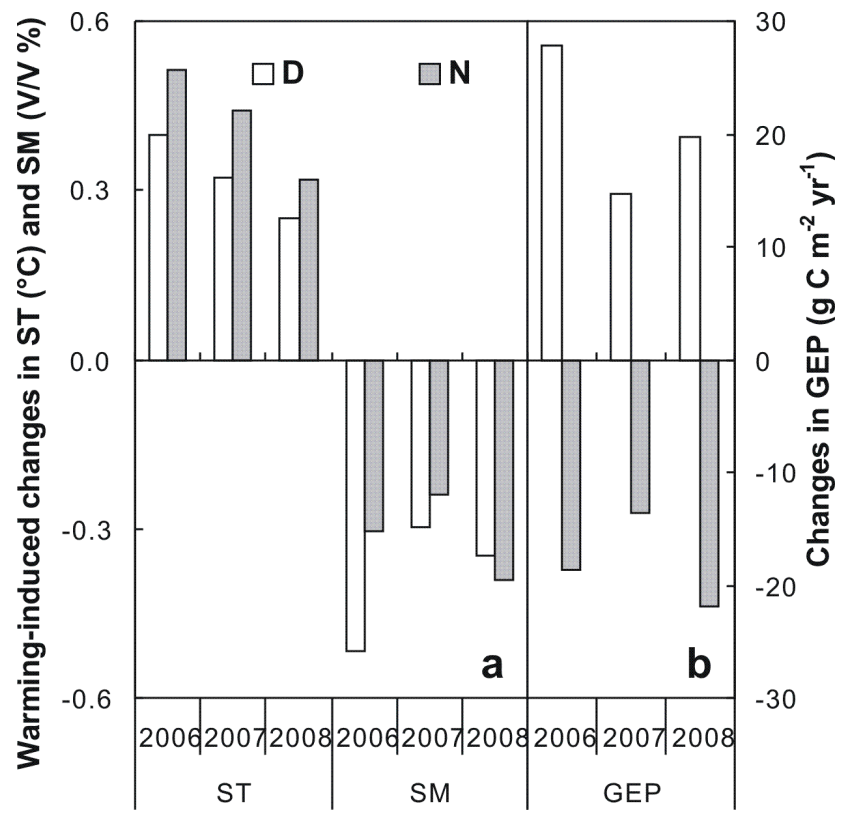

Fig. 1. Warming-induced absolute changes in (a) volumetric soil temperature (ST), soil moisture (SM), and (b) gross ecosystem productivity (GEP; here negative values represent $\mathrm{C}$ uptake). D, day warming; $\mathrm{N}$, night warming.

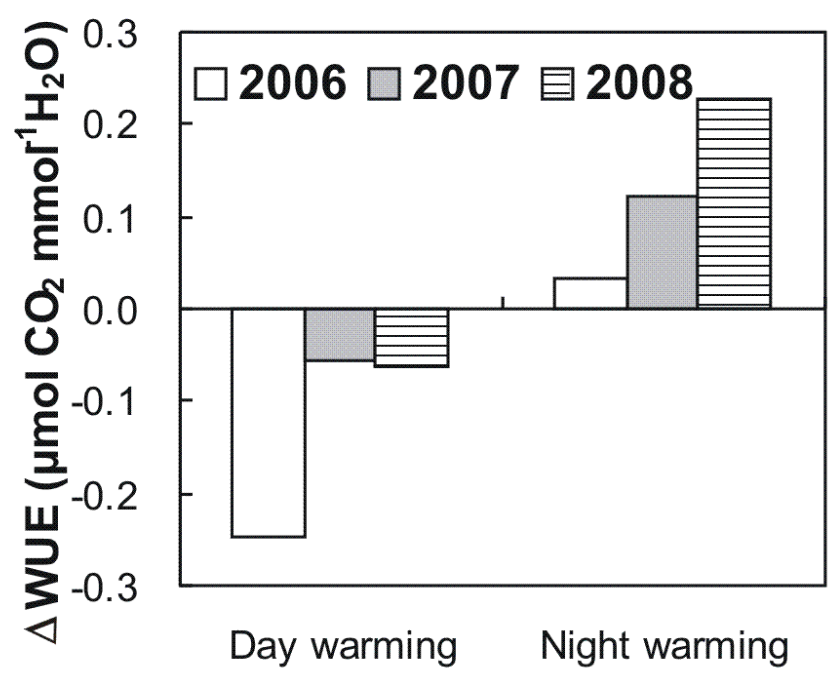

Fig. 2. Changes in ecosystem water use efficiency (WUE) induced by day and night warming over the three experimental years (20062008).

\subsection{Soil respiration}

Seasonal mean soil respiration ranged from $0.78 \mu \mathrm{mol} \mathrm{m}^{-2} \mathrm{~s}^{-1}$ (2007) to $2.56 \mu \mathrm{mol} \mathrm{m}^{-2} \mathrm{~s}^{-1}$ (2008) with an average of $1.69 \mu \mathrm{mol} \mathrm{m}^{-2} \mathrm{~s}^{-1}$ in the control plots. No main effect of day warming $(P=0.978)$ or its interaction with night warming $(P=0.124)$ was observed on soil respiration (Table 1, Fig. 3). However, night warming 


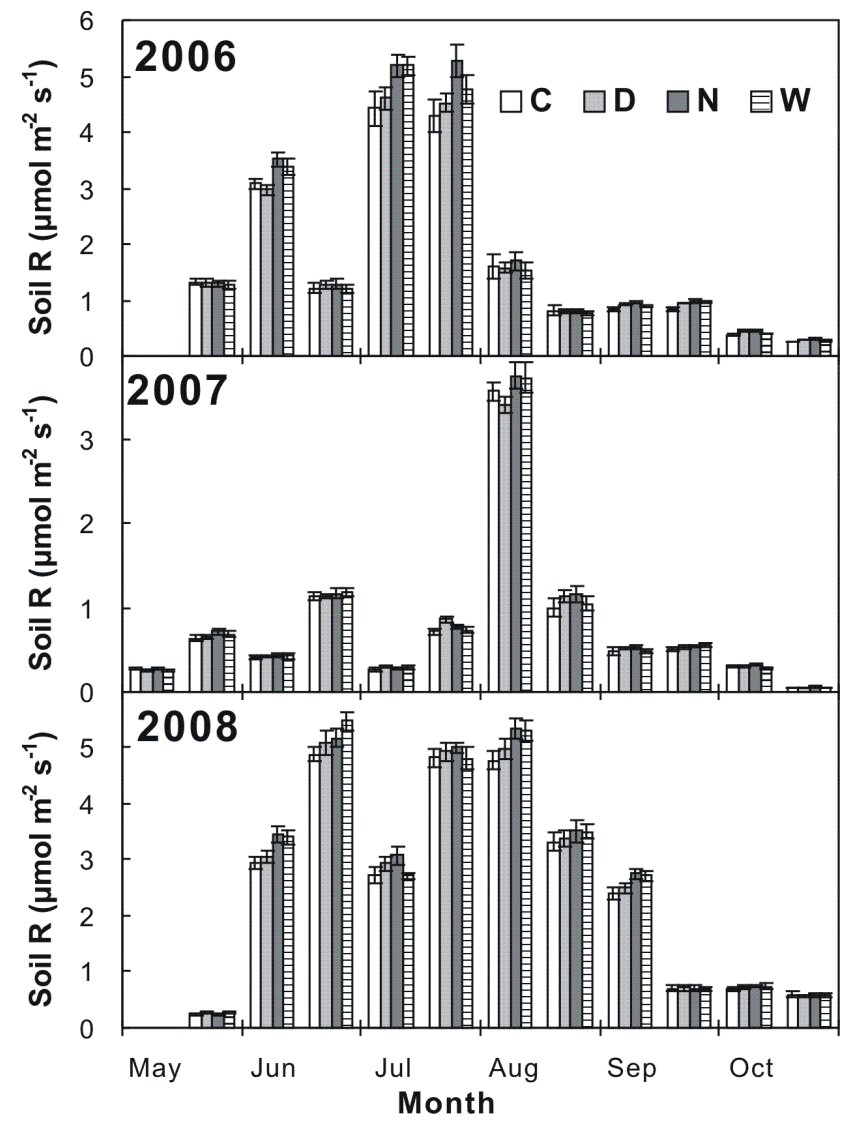

Fig. 3. Diurnal mean soil respiration $\left(\mu \mathrm{mol} \mathrm{m}^{-2} \mathrm{~s}^{-1}\right)$ under control (C), day warming (D), night warming $(\mathrm{N})$, and diurnal warming (W).

significantly stimulated soil respiration by $7.1 \%$ over the 3 growing seasons (Table 1, Fig. 3). There was no interaction between year and day warming $(P=0.807)$, night warming $(P=0.216)$, or their combination $(P=0.799)$ to influence soil respiration.

When divided the data into different months, we found that day warming showed no effects in any month (all $P>0.1)$ during the growing seasons. Night warming significantly increased soil respiration in June $(P=0.003)$ and July $(P=0.030)$, and showed marginally significant impacts in May $(P=0.052)$ and September $(P=0.058)$. In August and October, night warming showed no effect (all $P>0.1$ ) on soil respiration. No interaction between day and night warming was found in any month (all $P>0.05$ ) in this study (Table 2 ).

\subsection{Effects of soil microclimate and substrate supply on soil respiration}

When pooling together data in the control plots (without warming) of all the measured dates across the 3 growing seasons, we found that soil respiration (SR) increased exponentially with soil temperature $\left(r^{2}=0.16, P=0.018\right)$ and linearly with soil moisture $\left(r^{2}=0.49, P<0.0001\right)$ and GEE $\left(r^{2}=0.78\right.$,
Table 2. Results ( $P$-values) of two-way ANOVAs on the effects of day (D) and night (N) warming and their interactions on soil respiration from May to October across the 3 growing seasons.

\begin{tabular}{lrrrrrr}
\hline $\begin{array}{l}\text { Source of } \\
\text { variance }\end{array}$ & May & Jun & Jul & Aug & Sep & Oct \\
\hline $\mathrm{D}$ & 0.774 & 0.808 & 0.816 & 0.803 & 0.735 & 0.831 \\
$\mathrm{~N}$ & 0.052 & 0.003 & 0.030 & 0.192 & 0.058 & 0.315 \\
$\mathrm{D} \times \mathrm{N}$ & 0.356 & 0.534 & 0.081 & 0.653 & 0.269 & 0.110 \\
\hline
\end{tabular}

$P<0.0001)$. A combination $\left(\mathrm{SR}=a e^{b T} \times M \times \mathrm{GEE}+c\right)$ of soil temperature $(T)$, soil moisture $(M)$, and GEE explained $87.5 \%$ of the temporal variation in soil respiration.

Across the 48 collars, soil respiration (mean values over the 3 growing seasons) showed a positive linear dependence upon soil moisture $\left(r^{2}=0.10, P=0.034\right.$; Fig. $\left.4 \mathrm{~b}\right)$ and GEE $\left(r^{2}=0.21, P=0.001\right.$; Fig. $\left.4 \mathrm{c}\right)$. Stepwise multiple regression analyses demonstrated that $21.1 \%(P=0.001)$ of the spatial variation in soil respiration can be explained by GEE only. Simple regression showed that changes in soil respiration under day warming decreased linearly with the treatment-induced soil temperature differences $\left(r^{2}=0.17\right.$, $P=0.014$; Fig. 4d), but increased linearly with changes in GEE $\left(r^{2}=0.17, P=0.013\right.$; Fig. 4f). However, changes in soil respiration under night warming showed positive linear dependence upon changes in both soil moisture $\left(r^{2}=0.12\right.$, $P=0.036$; Fig. 4e $)$ and GEE $\left(r^{2}=0.16, P=0.018\right.$; Fig. 4 f $)$. Stepwise multiple regression analyses revealed that the treatment-induced changes in GEE can explain $16.7 \%$ and $15.8 \%$ of the changes in soil respiration under day and night warming, respectively.

During the period of peak growth in 2007 (from late July to late August), we analyzed the relationship between daily mean soil respiration and daytime mean leaf photosynthesis for S. krylovii, which is a predominant grass in this ecosystem. Daily mean soil respiration showed a positive linear $\left(r^{2}=0.25, P=0.013\right.$; Fig. 5a) dependence upon daytime mean leaf photosynthesis across the 24 experimental plots. Changes in daily mean soil respiration under both day $\left(r^{2}=0.44, P=0.018\right.$; Fig. 5b) and night $\left(r^{2}=0.35, P=0.045\right.$; Fig. 5b) warming increased linearly with treatment-induced changes in daytime mean leaf photosynthesis for $S$. krylovii.

\subsection{Relationships of the effects of diurnal warming with the summed effects of day and night warming on soil respiration and its controlling factors}

We plotted the summed changes in soil respiration (Fig. 6a), soil temperature (Fig. 6b), soil moisture (Fig. 6c), and GEE (Fig. 6d) under day and night warming (predicted values in the y-axis) against the observed changes under diurnal warming (observed values in the $\mathrm{x}$-axis). Slopes of day 

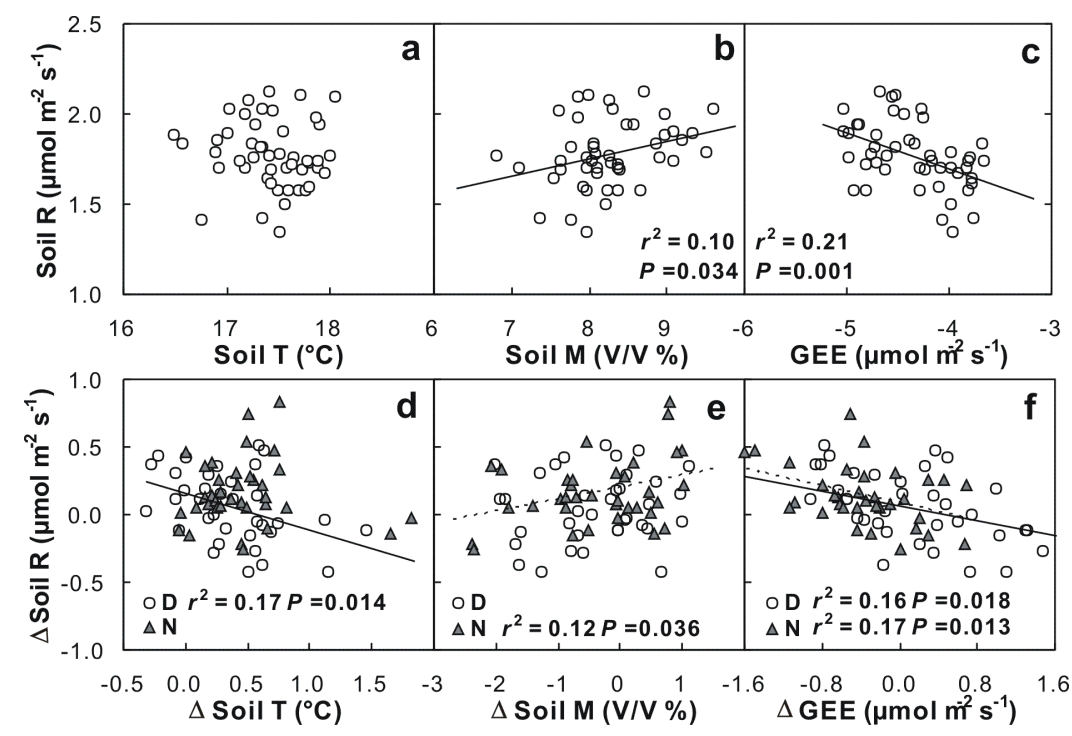

Fig. 4. Spatial dependence of mean soil respiration (soil R) over the 3 growing seasons on soil temperature (soil T; a), volumetric soil moisture (Soil M; b), and gross ecosystem exchange (GEE; c) across the 48 collars, and correlations between effects on soil respiration of day (d, e, and f; open cycles and solid lines) and night (d, e, and f; gray triangles and dashed lines) warming and the treatment-induced changes in soil moisture, temperature, and GEE (negative values represent $\mathrm{C}$ uptake) over the 3 growing seasons $(n=36$ ).

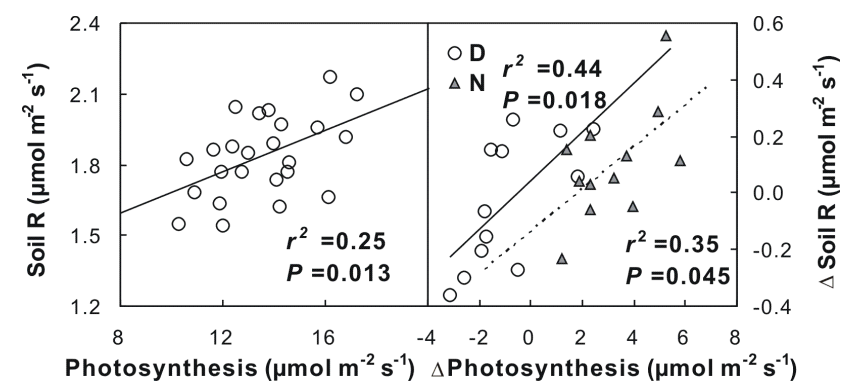

Fig. 5. Spatial dependence of mean soil respiration (soil R) on daytime mean leaf photosynthesis of S. krylovii (a); and correlations between effects on mean soil respiration of day (b, open cycles and solid lines) and night (b, gray triangles and dashed lines) warming and the treatment-induced changes in daytime mean leaf photosynthesis of S. krylovii during the peak growth period in 2007.

and night warming for soil respiration $(P=0.049)$ and GEE $(P<0.0001)$ were greater than the 1:1 line, whereas slopes for soil temperature $(P=0.711)$ and soil moisture $(P=0.080)$ did not differ from the 1:1 line.

We also calculated integrated values of soil respiration and GEP with daily mean soil respiration and GEE multiplied by the number of days before each measurement date over the growing seasons (1 May to 31 October) from 2006 to 2008. Soil respiration increased by $20.7 \mathrm{~g} \mathrm{C} \mathrm{m}^{-2} \mathrm{y}^{-1}$ under diurnal warming, which was not equal to its summed changes $\left(+40.0 \mathrm{~g} \mathrm{C} \mathrm{m}^{-2} \mathrm{y}^{-1}\right)$ under day $\left(+8.7 \mathrm{~g} \mathrm{C} \mathrm{m}^{-2} \mathrm{y}^{-1}\right)$ and night $\left(+31.3 \mathrm{~g} \mathrm{C} \mathrm{m}^{-2} \mathrm{y}^{-1}\right)$ warming alone. In addition, diurnal warming reduced
GEP by $2.8 \mathrm{~g} \mathrm{Cm}^{-2} \mathrm{y}^{-1}$, which is much less than the summed changes $\left(+24.6 \mathrm{~g} \mathrm{C} \mathrm{m}^{-2} \mathrm{y}^{-1}\right)$ in GEP under day $\left(-7.1 \mathrm{~g} \mathrm{C} \mathrm{m}^{-2} \mathrm{y}^{-1}\right)$ and night $\left(+31.7 \mathrm{~g} \mathrm{C} \mathrm{m}^{-2} \mathrm{y}^{-1}\right)$ warming alone.

\section{Discussion}

\subsection{Different effects of day and night warming on soil respiration}

Our study provides direct experimental evidence that day and night warming can differently affect soil respiration. Warming-induced changes in soil respiration are likely to result from changes in multiple processes (Shaver et al., 2000; Wan et al., 2007). For example, warming can directly stimulate root and microbial activities and respiration (Wan et al., 2007), and indirectly influence soil respiration via changes in ecosystem productivity (Rustad et al., 2001) and decreases in soil water availability (Harte et al., 1995; Wan et al., 2002; Liu et al., 2009). In this system, it has been demonstrated that warming-induced higher daytime temperature and vapour pressure deficit (VPD) could reduce leaf stomatal conductance, leading to lower canopy photosynthesis (Niu et al., 2008). In this study, the reduction in ecosystem WUE induced by day warming (Fig. 2) could exacerbate the negative impact of day warming on ecosystem $\mathrm{C}$ assimilation, which supplies $\mathrm{C}$ substrate for soil respiration. In addition, results from incubation experiments in the laboratory (Fig. 5 in Liu et al., 2009) demonstrated that microbial respiration reduced rapidly in response to a decrease in soil moisture, especially 
at low moisture levels. Thus, no response of soil respiration to day warming could result from the counteraction between direct positive impacts of temperature and negative influence of the treatment-induced decreases in soil moisture and GEP. Although night warming also reduced soil water availability in this study, night warming significantly enhanced ecosystem WUE (Fig. 2), suggesting that changes in plant production processes under night warming counteracts the negative impacts of treatment-induced water depletion. The contrasting responses of ecosystem $\mathrm{C}$ assimilation to day and night warming and their impacts on soil respiration responses (Fig. 4f) suggest that $\mathrm{C}$ substrate supply drives the differential responses of soil respiration to day and night warming.

The differential effects of day and night warming on ecosystem $\mathrm{C}$ assimilation could be explained by the hypothesis of sink regulation on plant photosynthesis, which suggests that activities of source photosynthetic production and sink growth appear to be closely coordinated (Paul and Foyer, 2001; Paul et al., 2001; McCormick et al., 2006). Wan et al. (2009) reported that day warming induced decreases in sugar $(21.4 \%)$ and starch (35.4\%) depletion, leading to reduction in GEP. In contrast, night warming increased leaf respiration of 3 dominant plant species, enhanced consumption of carbohydrates in the leaves, and subsequently stimulated photosynthesis and GEP in the following day (Wan et al., 2009).

Consistent with our finding, it has been reported by both historical data analyses and modeling simulations that day and night warming have differential impacts on terrestrial ecosystem processes (Ryan, 1991; Coughenour and Chen, 1997; Alward et al., 1999; Griffin et al., 2002; Turnbull et al., 2002, 2004). For example, long-term observations in a shortgrass steppe in Northern America showed significant responses of aboveground net primary production of different plant species to increased daily minimum, but not mean or maximum temperatures (Alward et al., 1999). Similar results were reported that increased daily minimum, but not maximum, temperatures significantly influence rice yield in Philippines (Peng et al., 2004). In the Southeastern US, reductions in corn yield have been shown to be associated with increases in daytime temperatures, whereas increased yield is related to night warming over 40 years (Rosenzweig and Tubiello, 1996). These results support the differential effects of day and night warming on plant photosynthesis and GEP in this experiment, suggesting day and night warming can differently affect substrate supply to soil respiration.

In the last ten years, a growing body of evidence from case studies of tree girdling (Högberg et al., 2001) and shading or clipping (Craine et al., 1999; Wan and Luo, 2003; Bahn et al., 2006), and large-scale synthesized research (Bahn et al., 2008) has demonstrated regulation of ecosystem $\mathrm{C}$ assimilation on soil respiration. In this study, at both leaf and ecosystem levels, not only soil respiration showed positive dependence upon photosynthesis, but also treatment-induced changes in soil respiration increased linearly with the in-
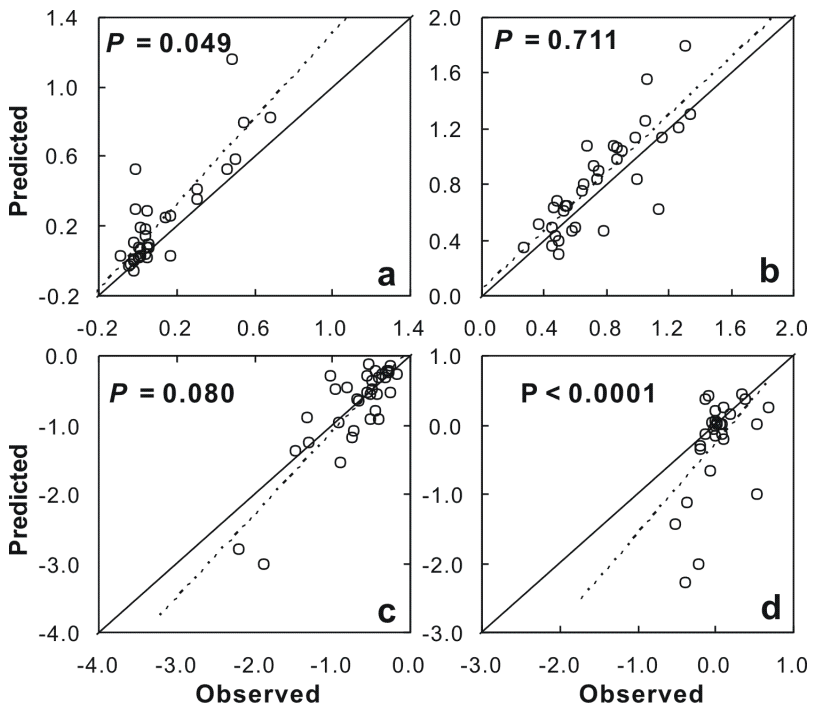

Fig. 6. Predicted and observed effects of day and night warming on (a) daily mean soil respiration $\left(\mu \mathrm{mol} \mathrm{m}^{-2} \mathrm{~s}^{-1}\right)$, (b) daily mean soil temperature $\left({ }^{\circ} \mathrm{C}\right),(\mathbf{c})$ volumetric soil moisture $(\mathrm{V} / \mathrm{V} \%)$, and (d) mean gross ecosystem exchange (GEE, $\mu \mathrm{mol} \mathrm{m}^{-2} \mathrm{~s}^{-1}$ ). Predicted values are the summed changes under day and night warming, and the observed values are the changes under diurnal warming. If $P>0.05$, the slopes for the linear function (dashed lines) overlap with the 1:1 line (solid lines), suggesting that the effects of diurnal warming are equal to the summed effects of day and night warming. If $P<0.05$, the slopes for the linear function significantly differ from the 1:1 line, suggesting that the effects of diurnal warming are not equal to the summed effects of day and night warming. The individual regression in the four panels are all significant $\left(\mathrm{a}, r^{2}=0.73\right.$, $P<0.0001 ; \quad b, r^{2}=0.69, P<0.0001 ; \mathrm{c}, r^{2}=0.72, P<0.0001 ; \mathrm{d}$, $\left.r^{2}=0.27, P=0.004\right)$.

crease in photosynthesis. The observations in the previous studies and the present study indicate that simulation and prediction of soil respiration in response to climate change should take into consideration of changes in biotic factors (plant growth and substrate supply) in addition to those of abiotic factors (temperature and moisture; Wan et al., 2007).

\subsection{Are the effects of diurnal warming equal to the summed effects of day and night warming?}

Greater summed effect of day and night warming on soil respiration than the effects of diurnal warming $(P=0.001$; Fig. 6a) demonstrated that the effects of diurnal warming were not equal to and could not be predicted by the summed effects of day and night warming in this system. Most experimental studies have been conducted with diurnal or constant warming and some models (Cox et al. 2000; Fung et al. 2005; King et al. 2006) often use daily, monthly, and annual mean temperatures as the climate drivers in simulating and predicting the responses and feedbacks of terrestrial ecosystem $\mathrm{C}$ cycling to global warming. Our results suggest 
that future experimental and model studies should incorporate the differential effects of day and night warming into the projection of the climate-carbon feedback.

It has long been identified that soil temperature, soil moisture and $\mathrm{C}$ substrate supply are the main controlling factors over soil respiration in terrestrial ecosystems (Raich and Tufekcioglu, 2000; Rustad et al., 2001; Högberg et al., 2001; Wan et al., 2007) and the fundamental parameters in predicting soil respiration responses to global change (Cox et al., 2000; Reichstein et al., 2005; Trumbore, 2006). The differential effects of day and night warming on GEE in this study suggest that $\mathrm{C}$ substrate supply could be very important in regulating the effects of day and night warming on soil respiration in this ecosystem. In this study, averaged across the 3 growing seasons and the 3 dominant species (A. cristatum, $S$. krylovii, and A. frigida), diurnal warming showed no effect on nighttime sugar or starch depletion (all $P>0.1$; see Fig. 5 in Wan et al., 2009). Therefore, the overcompensation of plant photosynthesis observed under night warming is unlikely to occur in the following day under diurnal warming. In fact, diurnal warming did not change GEE $(P=0.874$; Repeat-measured ANOVA) across the 3 growing seasons in this study. Thus, the differential effects of day and night warming on GEE could be due to the disappearance of plant photosynthetic overcompensation when the ecosystem is exposed to diurnal warming.

\subsection{How much do the changes in soil respiration affect ecosystem carbon balance?}

Because temperature influences all terrestrial $\mathrm{C}$ processes, climate warming is likely to enhance ecosystem C fluxes, which potentially feedback to climate change (Luo, 2007). It is expected that if $\mathrm{C}$ stored in soil is transferred to the atmosphere by elevated temperature, a positive feedback to climate change may occur. Conversely, if increases in plantderived $\mathrm{C}$ inputs to soils exceed increases in soil respiration, the feedback will be negative (Davidson and Janssens, 2006). In this study, soil respiration was significantly increased by night warming (Table 1, Fig. 3). Similarly, nighttime warming increased nighttime leaf respiration of two dominant species by $36.3 \%$, but daytime warming decreased it by $14.0 \%$ (Wan et al., 2009). However, this does not necessarily mean a positive feedback to climate change in this ecosystem. In fact, we have found that $\mathrm{C}$ sequestration in this system is enhanced by photosynthetic overcompensation under night warming (Wan et al., 2009). In addition, over the past 53 years (1953-2005), local climate in our study area (Duolun County, Inner Mongolia, China) experienced asymmetrical diurnal warming $\left(0.57,0.45\right.$, and $0.30^{\circ} \mathrm{C}$ increases in daily minimum, mean, and maximum temperature per decade; Wan et al., 2009, Appendix E). Therefore, irrespective of enhancement in soil respiration under night warming, a negative feedback to climate change will occur because of the greater stimulation of ecosystem $\mathrm{C}$ assimila- tion (Table 1, Fig. 1b) under night warming in the temperate steppe in northern China (Wan et al., 2009). The findings in this and a previous study (Wan et al., 2009) indicate that effects of climate warming on ecosystem $\mathrm{C}$ cycling can not be fully evaluated without taking into consideration of all ecosystem $\mathrm{C}$ processes.

\section{Conclusions}

This study has revealed the differential effects of day and night warming on soil respiration, which could have resulted from their different effects on ecosystem $\mathrm{C}$ assimilation and substrate supply. Warming is often applied as a constant elevation of temperature above ambient temperature both in field experiments and modeling studies in spite of the observed greater night warming trend (Karl et al., 1991; Easterling et al., 1997; IPCC, 2001; Zhou et al., 2007). Our observations indicate that influences of day and night warming on ecosystem $\mathrm{C}$ flux are not equivalent in our system and that the effects of diurnal warming can not be predicted by the summed effects of day and night warming. These findings highlight the need for future research to incorporate differential impacts of day and night warming on terrestrial ecosystem $\mathrm{C}$ processes.

Acknowledgements. This study was financially supported by the National Natural Science Foundation of China (90511006, 30590382, and 30821062), Chinese Academy of Sciences (Hundred Talents Program), and State Key Laboratory of Vegetation and Environmental Changes. We thank two anonymous reviewers for their thoughtful comments, which helped in improving the manuscript. Authors thank S. Niu, Z. Li, W. Cheng, Y. Zhang, H. Yang, D. Lin, T. Li, Y. Li, and C. Bai for their help in the field measurement; and W. Zhang for the help in English writing.

Edited by: G. Wohlfahrt

\section{References}

Alward, R. D., Detling, J. K., and Milchunas, D. G.: Grassland vegetation changes and nocturnal global warming, Science, 316, 229-231, 1999.

Bahn, M., Knapp, M., Garajova, Z., Pfahringer, N., and Cernusca, A.: Root respiration in temperate mountain grasslands differing in land use, Glob. Change Biol., 12, 995-1006, 2006.

Bahn, M., Rodeghiero, M., Anderson-Dunn, M., Dore, S., Gimeno, C., Drösler, M., Williams, M., Ammann, C., Berninger, F., Flechard, C., Jones, S., Balzarolo, M., Kumar, S., Newesely, C., Priwitzer, T., Raschi, A., Siegwolf, R., Susiluoto, S., Tenhunen, J., Wohlfahrt, G., and Cernusca, A.: Soil respiration in European grasslands in relation to climate and assimilate supply, Ecosystems, 11, 1352-1367, 2008.

Beier, C., Emmett, B. A., Peñuelas, J., Schmidt, I. K., Tietema, A., Estiarte, M., Gundersen, P., Llorens, L., Riis-Nielsen, T., Sowerby, A., and Gorissen, A.: Carbon and nitrogen cycles in European ecosystems respond differently to global warming, Sci. Total Environ., 407, 692-697, 2008. 
Coughenour, M. B. and Chen, D.: Assessment of grassland ecosystem responses to atmospheric change using linked plant-soil process models, Ecol. Appl., 7, 802-827, 1997.

Cox, P. M., Betts, R. A., Jones, C. D., Spall, S. A., and Totterdell, I. J.: Acceleration of global warming: due to carbon-cycle feedbacks in a coupled climate model, Nature, 408, 184-187, 2000.

Craine, J. M., Wedin, D. A., and Chapin III, F. S.: Predominance of ecophysiological controls on soil $\mathrm{CO}_{2}$ flux in a Minnesota grassland, Plant Soil, 207, 77-86, 1999.

Davidson, E. A. and Janssens, I. A.: Temperature sensitivity of soil carbon decomposition and feedbacks to climate change, Nature, 440, 165-173, 2006

Dhakhwa, G. B. and Campbell, C. L.: Potential effects of differential day-night warming in global climate change on crop production, Climatic Change, 40, 647-667, 1998.

Easterling, D. R., Horton, B., Jones, P. D., Peterson, T. C., Karl, T. R., Parker, D. E., Salinger, M. J., Razuvayev, V., Plummer, N., Jamason, P., and Folland, C. K.: Maximum and minimum temperature trends for the globe, Science, 277, 364-367, 1997.

Fung, I. Y., Doney, S. C., Lindsay, K., and John, J.: Evolution of carbon sinks in a changing climate, P. Natl. Acad. Sci., 102, 1120111206, 2005.

Griffin, K. L., Turnbull, M., Murthy, R., Lin, G., Adams, J., Farnsworth, B., Mahato, T., Bazin, G., Potasnak, M., and Berry, J. A.: Leaf respiration is differentially affected by leaf vs. standlevel night-time warming, Glob. Change Biol., 8, 479-485, 2002.

Harte, J. and Shaw, R.: Shifting dominance within a montane vegetation community: results of a climate-warming experiment, Science, 267, 876-880, 1995.

Högberg, P., Nordgren, A., Buchmann, N., Taylor, A. F. S., Ekblad, A., Högberg, M. N., Nyberg, G., Ottosson-Löfvenlus, M., and Read, D. J.: Large-scale forest girdling shows that current photosynthesis drives soil respiration, Nature, 411, 789-792, 2001.

IPCC: Climate Change 2001: The Scientific Basis, edited by: Hallgren R. and Nyenzi, B., Cambridge University Press, New York, 2001.

IPCC: Climate Change 2007: The Physical Science Basis, Cambridge University Press, Cambridge, UK, 2007.

Karl, T. R., Kukla, G., Razuvayev, V. N., Changery, M. J., Quayle, R. G., Heim Jr., R. R., Easterling, D. R., and Fu, C. B.: Global warming - evidence for asymmetric diurnal temperature-change, Geophys. Res. Lett., 18, 2253-2256, 1991.

King, A. W., Gunderson, C. A., Post, W. M., Weston, D. J., and Wullschleger, S. D.: Plant respiration in a warmer world, Science, 312, 536-537, 2006.

Liu, W. X., Zhang, Z., and Wan, S. Q.: Predominant role of water in regulating soil and microbial respiration and their responses to climate change in a semiarid grassland, Glob. Change Biol., 15, 184-195, 2009.

Lloyd, J. and Taylor, J. A.: On the temperature dependence of soil respiration, Funct. Ecol., 8, 315-323, 1994.

Lobell, D. B.: Changes in diurnal temperature rand and national cereal yields, Agr. Forest Meteorol., 145, 229-238, 2007.

Lobell, D. B. and Ortiz-Monasterio, J. I.: Impacts of day versus night temperatures on spring wheat yields: A comparison of empirical and CERES model predictions in three locations, Agron. J., 99, 469-477, 2007.

Luo, Y. Q.: Terrestrial carbon-cycle feedback to climate warming, Annu. Rev. Ecol. Syst., 38, 683-712, 2007.
Luo, Y. Q. and Zhou, X. H.: Soil Respiration and the Environment, Academic Press, San Diego, Academic/Elsevier, 328 pp., 2006.

Luo, Y. Q., Sherry, R., Zhou, X. H., and Wan, S. Q.: Terrestrial carbon-cycle feedback to climate warming: Experimental evidence on plant regulation and impacts of biofuel feedstock harvest, Glob. Change Biol.-Bioenergy, 1, 62-74, 2009.

McCormick, A. J., Cramer, M. D., and Watt, D. A.: Sink strength regulate photosynthesis in sugarcane, New Phytol., 171, 759$770,2006$.

Nicholls, N.: Increased Australian wheat yield due to recent climate trends, Nature, 387, 484-485, 1997.

Niu, S. L., Wu. M. Y., Han, Y., Xia, J. Y., Li, L. H., and Wan, S. Q.: Water-mediated responses of ecosystem carbon fluxes to climatic change in a temperate steppe, New Phytol., 177, 209-219, 2008.

Paul, M. J. and Foyer, C. H.: Sink regulation of photosynthesis, J. Exp. Bot., 52, 1381-1400, 2001.

Paul, M. J., Pellny, T. K., and Goddijn, O.: Enhancing photosynthesis with sugar signals, Trend. Plant Sci., 6, 197-200, 2001.

Peng, S. B., Huang, J. L., Sheehy, J. E., Lazza, R. C., Visperas, R. M., Zhong, X., Centeno, G. S., Khush, G. S., and Cassman, K. G.: Rice yields decline with higher night temperature from global warming, P. Natl. Acad. Sci., 101, 9971-9975, 2004.

Raich, J. W. and Tufekcioglu, A.: Vegetation and soil respiration: correlations and controls, Biogeochemistry, 48, 71-90, 2000.

Reichstein, M., Subke, J. A., Angeli, A. C., and Tenhunen, J. D.: Does the temperature sensitivity of decomposition of soil organic matter depend upon water content, soil horizon, or incubation time?, Glob. Change Biol., 11, 1754-1767, 2005.

Rosenzweig, C. and Tubiello, F. N.: Effects of changes in minimum and maximum temperature on wheat yields in the central US-A simulation study, Agr. Forest Meteorol., 80, 215-230, 1996.

Rustad, L. E., Campbell, J. L., Marion, G. M., Norby, R. J., Mitchell, M. J., Hartley, A. E., Cornelissen, J. H. C., and Gurevitch, J.: A meta-analysis of the response of soil respiration, net nitrogen mineralization, and aboveground plant growth to experimental ecosystem warming, Oecologia, 126, 543-562, 2001.

Rustad, L. E.: The response of terrestrial ecosystems to global climate change: Towards an integrated approach, Sci. Total Environ., 404, 222-235, 2008.

Ryan, G. R.: Effects of climate change on plant respiration, Ecol. Appl., 1, 157-167, 1991.

Schlenker, W. and Roberts, M. J.: Nonlinear effects of weather on corn yields, Rev. Agr. Econ., 28, 391-398, 2006.

Shaver, G. R., Canadell, J., Chapin III, F. S., Gurevitch, J., Harte, J., Henry, G., Ineson, P., Jonasson, S., Melillo, J., Pitelka, L., and Rustad, L.: Global warming and terrestrial ecosystems: A conceptual framework for analysis, Bioscience, 50, 871-882, 2000.

Stooksbury, D. E. and Michaels, P. J.: Climate change and largearea corn yield in the southeastern United States, Agron. J., 86, 564-569, 1994.

Tang, J., Baldocchi, D. D., and Xu, L.: Tree photosynthesis modulates soil respiration on a diurnal time scale, Glob. Change Biol., 11, 1298-1304, 2005.

Trumbore, S.: Carbon respired by terrestrial ecosystems-recent progress and challenges, Glob. Change Biol., 12, 141-153, 2006.

Turnbull, M. H., Murthy, R., and Griffin, K. L.: The relative impacts of daytime and nighttime warming on photosynthetic capacity in Populus deltoids, Plant Cell Environ., 25, 1729-1737, 2002.

Turnbull, M. H., Tissue, D. T., Murthy, R., Wang, X., Sparrow, A. 
D., and Griffin, K. L.: Nocturnal warming increase photosynthesis at elevated $\mathrm{CO}_{2}$ partial pressure in Populus deltoids, New Phytol., 161, 819-826, 2004.

Volder, A., Edwards, E. J., Evans, J. R., Robertson, B. C., Schortemeyer, M., and Gifford, R. M.: Does greater night-time, rather than constant, warming alter growth of managed pasture under ambient and elevated atmospheric $\mathrm{CO}_{2}$ ?, New Phytol., 162, 397411, 2004.

Volder, A., Gifford, R. M., and Evans, J. R.: Effects of elevated atmospheric $\mathrm{CO}_{2}$, cutting frequency, and differential day/night atmospheric warming on root growth and turnover of Phalaris swards, Glob. Change Biol., 13, 1040-1052, 2007.

Vose, R. S., Easterling, D. R., and Gleason, B.: Maximum and minimum temperature trends for the globe: an update through 2004, Geophys. Res. Lett., 32, L23822, doi:10.1029/2005GL024379, 2005.

Wan, S. Q. and Luo, Y. Q.: Substrate regulation of soil respiration in a tallgrass prairie: results of a clipping and shading experiment, Global Biogeochem. Cy., 17, 1054, doi:10.1029/2002GB001971, 2003.

Wan, S. Q., Luo, Y. Q., and Wallace, L. L.: Changes in microclimate induced by experimental warming and clipping in tallgrass prairie, Glob. Change Biol., 8, 754-768, 2002.
Wan, S. Q., Norby, R. J., Ledford, J., and Weltzin, J. F.: Responses of soil respiration to elevated $\mathrm{CO}_{2}$, air warming, and changing soil water availability in a model old-field grassland, Glob. Change Biol., 13, 2411-2424, 2007.

Wan, S. Q., Xia, J. Y., Liu, W. X., and Niu, S. L.: Photosynthetic over-compensation under nocturnal warming enhances grassland carbon sequestration, Ecology, 90, 2700-2710, 2009.

Xia, J. Y., Niu, S. L., and Wan, S. Q.: Response of ecosystem carbon exchange to warming and nitrogen addition during two climatologically contrasting growing seasons in a temperate steppe, Glob. Change Biol., 15, 1544-1556, 2009.

Zavaleta, E. S., Shaw, M. R., Chiariello, N. R., Mooney, H. A., and Field, C. B.: Additive effects of simulated climate changes, elevated $\mathrm{CO}_{2}$, and nitrogen deposition on grassland diversity, $\mathrm{P}$. Natl. Acad. Sci., 100, 7650-7654, 2003.

Zhou, L., Dickinson, R. E., Tian, Y., Vose, R. S., and Dai, Y.: Impact of vegetation removal and soil aridation on diurnal temperature range in a semiarid region: application to the Sahel, P. Natl. Acad. Sci., 104, 17937-17942, 2007.

Ziska, L. H. and Manalo, P. A.: Increasing night temperature induces sterility in tropical rice, Aust. J. Plant Physiol., 23, 791794, 1996. 